\title{
Necrotising fasciitis as atypical presentation of infection with emerging Neisseria meningitidis serogroup W (MenW) clonal complex 11, the Netherlands, March 2017
}

A Russcher ${ }^{1}$, E Fanoy ${ }^{23}$, GDJ van Olden ${ }^{4}$, AD Graafland ${ }^{5}$, A van der Ende ${ }^{6}$, MJ Knol ${ }^{3}$

1. Department of Medical Microbiology, Meander Medical Centre, Amersfoort, the Netherlands

2. Public Health Service Region Utrecht, Zeist, the Netherlands

3. Centre for Infectious Diseases Control, National Institute for Public Health and the Environment, Bilthoven, the Netherlands

4. Department of Surgery, Meander Medical Centre, Amersfoort, the Netherlands

5. Department of Intensive Care, Meander Medical Centre, Amersfoort, the Netherlands

6. Department of Medical Microbiology and the Netherlands Reference Laboratory for Bacterial Meningitis, Academic Medical Center, Amsterdam, the Netherlands

Correspondence: Anne Russcher (a.russcher@meandermc.nl)

Citation style for this article:

Russcher A, Fanoy E, van Olden GDJ, Graafland AD, van der Ende A, Knol MJ. Necrotising fasciitis as atypical presentation of infection with emerging Neisseria meningitidis serogroup W (MenW) clonal complex 11, the Netherlands, March 2017. Euro Surveill. 2017;22(23):pii=30549. D0I: http://dx.doi.org/10.2807/15607917.ES.2017.22.23.30549

Article submitted on 14 May 2017 / accepted on 30 May 2017 / published on 08 June 2017

In March 2017, a patient with necrotising fasciitis caused by Neisseria meningitidis serogroup W (MenW) clonal complex 11 was diagnosed in the Netherlands. Unusual and severe presentations of MenW infections are common in the current European epidemic. In the Netherlands, the incidence of MenW infections increased 10 -fold, from an average of 0.03 per 100,000 population in 2002-2014 to 0.29 in 2016. Awareness of atypical presentations enables timely adequate treatment and public health action.

\section{Case description and microbiological findings}

In March 2017 (day o), a man in his early 6oies consulted his general practitioner (GP) because of a painful, red and swollen ankle since 1 day. Five days before his GP visit, he had experienced a fever that lasted 2 days and was accompanied by nausea and vomiting, from which he recovered spontaneously. The GP diagnosed a first episode of gout and prescribed a nonsteroidal anti-inflammatory drug (NSAID). One day later (day 1), the patient visited the emergency department of a local hospital as the redness had spread and now covered his left lower leg up to the knee (Figure). Blistering was present on the ankle. Physical examination also revealed a red, painful area on his right elbow that the patient had been unaware of up until that moment. Prior to this illness, the patient had not travelled abroad, had generally been in good health and had an unremarkable medical history.

Emergency surgery was performed immediately because of the clinical suspicion of a necrotising fasciitis. Antibiotic treatment consisting of benzylpenicillin, 20 million units per day (MU/day) intravenously (IV), and clindamycin, $600 \mathrm{mg}$ IV four times daily, was initiated. During surgery, extensive necrosis of subcutis and fascia of the lower leg was present and a fasciectomy of the total lower leg was necessary. Intraoperative Gram-staining of fascia tissue of both the leg and elbow showed the presence of Gramnegative diplococci and ceftriaxone, $2 \mathrm{~g}$ IV twice daily, was started.

Post-operatively, the patient was admitted to the intensive care unit with septic shock and received circulatory support with noradrenalin and mechanical ventilation for 48 hours. A second-look operation within 12 hours after the first operation ensured that the first debridement had been sufficient. The following day, tissue cultures were positive for Neisseria meningitidis. Identification was performed by MaldiToF mass spectrometry (Bruker, Bremen, Germany). Susceptibility testing by E-test (Biomerieux, Marcy l'Etoile, France) with minimal inhibitory concentrations (MIC) in brackets showed susceptibility to penicillin $(0.06 \mathrm{mg} / \mathrm{L})$, ceftriaxone $(0.04 \mathrm{mg} / \mathrm{L})$, rifampicin (0.032 mg/L) and ciprofloxacin (0.008 mg/L) [1]. Typing at the Netherlands Reference Laboratory for Bacterial Meningitis revealed a serogroup W subtype P1.5,2:F1-1 belonging to the hypervirulent clonal complex 11.

\section{Treatment and follow-up measures}

When results of susceptibility testing became available, the patient was treated with benzylpenicillin, 20 $\mathrm{MU} /$ day, later lowered to $12 \mathrm{MU} /$ day for another 7 days. 


\section{FIGURE 1}

Blister on left ankle as clinical sign in case of necrotising fasciitis due to emerging Neisseria meningitidis serogroup W, the Netherlands, March 2017

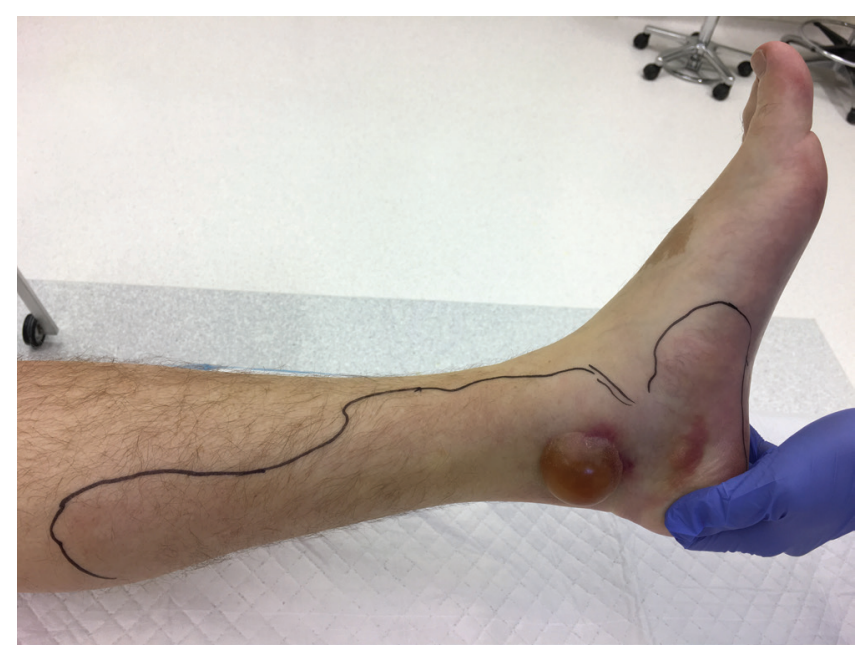

Split skin grafting was performed on his leg. At the time of writing, the patient was recovering well.

The regional public health service (PHS) was contacted the day after admission (day 2) to evaluate the need for prophylactic antibiotic treatment and MenACWY vaccination of close contacts, but such measures were not needed as the patient had lived alone during the week before the onset of disease and there were no close contacts otherwise. The patient received a MenACWY vaccination to prevent a (re)infection in the following $3-5$ years $[2,3]$. The case was notified by the PHS to the National Institute for Public Health and the Environment (RIVM) by the mandatory surveillance system. The Netherlands Early Warning Committee (NEWC) discussed the remarkable clinical presentation of this MenW case and communicated it to Dutch medical professionals via the weekly NEWC report.

\section{Epidemiological situation in the Netherlands}

Before 2015, the incidence of MenW disease was very low in the Netherlands, with an average annual incidence of 0.03 per 100,000 population from 2002 to 2014 (range: $0.01-0.04$ per 100,000 population). The incidence increased to 0.05 per 100,000 population ( $n=9$ cases) in 2015 and 0.29 per 100,000 population ( $\mathrm{n}=50$ cases) in 2016 [4]. The increase started in October 2015 and up until 1 April 2017, 79 MenW cases were reported. In 74 of 79 cases, the finetype could be determined (1 PCR-positive, 73 cultured isolates). It was $\mathrm{P}_{1.2,5}: \mathrm{F}_{1-1}$ in 68 of 74 cases (92\%). This finetype is associated with hypervirulent clonal complex 11 [5]. Of the remaining five cases (all PCR-positive, culture-negative), not enough material was available to perform typing. MenW incidence was highest among persons aged 65 years or older $(0.65 / 100,000 ; n=30)$, followed by $15-24$-year-olds $(0.48 / 100,000 ; n=15)$. Of 79 MenW cases, nine died (11\%): four of them were $15^{-24}$ years old, two were 45-64 years old and three were 65 years or older. The clinical manifestation was known for 71 cases: 32 had septicaemia (45\%), 14 had meningitis (20\%), and seven had both septicaemia and meningitis (10\%). The other cases had other clinical manifestations including bacteraemic pneumonia $(n=12$; $17 \%)$, septic arthritis $(n=4 ; 6 \%)$, pericarditis $(n=1)$ and necrotising fasciitis ( $n=1$, the case described above). To our knowledge, three patients with septicaemia, one of whom died, presented predominantly with gastrointestinal symptoms. None of the cases were epidemiologically related and there is no geographical clustering.

\section{Discussion}

Infections due to MenW may present differently from the classical clinical presentation of $N$. meningitidis such as meningitis or septicaemia; for example, gastrointestinal presentations have been reported with MenW $[6,7]$. Necrotising fasciitis can be caused by various bacterial pathogens, but in monomicrobial infections, haemolytic Streptococci group A are most commonly identified as the cause [8]. N. meningitidis as the causative agent in necrotising fasciitis is extremely rare [9], although there are some reports on severe cellulitis being caused by $N$. meningitidis $[10,11]$.

In the reported case, the presence of infectious foci on both the leg and arm strongly suggests haematogenous spread, probably from nasopharyngeal carriage as no other apparent focus was identified. Blood cultures remained negative, but these were mistakenly drawn after antimicrobial treatment had already been started. The preceding gastrointestinal symptoms could have been related to the MenW infection as was recently described by others $[6,7]$, but they might be a remarkable coincidence as the necrotising fasciitis symptoms did not develop until 3 days later. Reported cases of MenW with gastrointestinal symptoms quickly progressed into septicaemia [7].

Other European countries have also reported MenW cases due to this hypervirulent strain $[5,12]$.

A similar increase in incidence and a similar age distribution in MenW cases has been noted in the United Kingdom (UK) starting in the epidemiological year 2009/2010. Campbell et al. report a case fatality rate of $12 \%(21 / 170)$ in $2014 / 15$ [12]. A similar case fatality rate of $12 \%(15 / 129)$ was reported for the previous period 2010/11-2012/13 (three epidemiological years) [13]. These findings led to emergency vaccination of 13 to 18 -year-olds with a MenACWY vaccine [14]. The first results of this programme seem promising, with an observed $69 \%$ reduction of predicted cases in the cohort offered vaccination at a vaccination coverage of only $37 \%$ [15]. Although this particular case of necrotising fasciitis developed in a patient in their 6oies, introduction of a vaccination programme against MenW in the Netherlands and possibly other European countries 
might be justified based on the comparable epidemiological pattern and high case fatality rate.

In conclusion, our case underscores the unusual presentation and severity of MenW infections, mostly caused by the hypervirulent clonal complex 11, in the current epidemic. Physicians should be vigilant for rare presentations of MenW infections considering the necessity of prompt diagnosis for optimal treatment. Based on the current epidemiology, inclusion of vaccination against MenW disease in the Dutch national immunisation programme should be discussed.

\section{Acknowledgements}

This work was not funded by external sources.

\section{Conflict of interest}

None declared.

\section{Authors' contributions}

$A R, E F$ and $M K$ wrote the first draft of the manuscript. All authors critically read and revised the manuscript. AR, GvO and AG participated in clinical management of the patient. $A R$ and AvdE were responsible for laboratory tests. EF was responsible for public health policies. MK and AvdE collected and analysed all MenW cases in the Netherlands.

\section{References}

1. The European Committee on Antimicrobial Susceptibility Testing (EUCAST). Breakpoints tables for interpretation of MICs and zone diameters, Version 7.1, Växjö: EUCAST. 2017. Available from: http://www.eucast.org

2. Baxter R, Reisinger K, Block SL, Izu A, Odrljin T, Dull P. Antibody persistence and booster response of a quadrivalent meningococcal conjugate vaccine in adolescents.J Pediatr. 2014;164(6):1409-15. DOI: 10.1016/j.jpeds.2014.02.025 PMID: 24657122

3. Cohn AC, MacNeil JR, Harrison LH, Lynfield R, Reingold A, Schaffner W, et al. Effectiveness and Duration of Protection of One Dose of a Meningococcal Conjugate Vaccine. Pediatrics. 2017;139(2):e20162193. DOI: 10.1542/peds.2016-2193 PMID: 28100689

4. Knol M, Ruijs WLM, Melker HE, Berbers GAM, van der Ende A. Sudden increase of invasive meningococcal disease serogroup W in 2015 and 2016 [Plotselinge toename van invasieve meningokokkenziekte serogroep W in 2015 en 2016]. Infectieziekten Bulletin. 2017;28(1):23-8. Dutch. Available from: http://www.rivm.nl/dsresource?objectid=9fcfeeo7c3dc-4af8-9437-7e328a66469c\&type=pdf\&disposition=inli ne

5. Lucidarme J, Scott KJ, Ure R, Smith A, Lindsay D, Stenmark $B$, et al. An international invasive meningococcal disease outbreak due to a novel and rapidly expanding serogroup W strain, Scotland and Sweden, July to August 2015. Euro Surveill. 2016;21(45):30395. DOI: 10.2807/1560-7917. ES.2016.21.45.30395 PMID: 27918265

6. Wunderink HF, Vlasveld I, Knol MJ, van der Ende A, van Essen E, Kuijper E. Diarree en sepsis door Neisseria meningitidis serogroep W.[Diarrhoea and septicaemia caused by Neisseria meningitidis serogroup W].Ned Tijdschr Geneeskd. Dutch. Forthcoming.

7. Campbell H, Parikh SR, Borrow R, Kaczmarski E, Ramsay ME, Ladhani SN. Presentation with gastrointestinal symptoms and high case fatality associated with group W meningococcal disease (MenW) in teenagers, England, July 2015 to January 2016. Euro Surveill. 2016;21(12):30175. DOI: 10.2807/1560-7917. ES.2016.21.12.30175 PMID: 27035055

8. Pasternack MS, Schwartz MN. Cellulitis, Necrotizing Fasciitis, and Subcutaneous Tissue Infections. In: Bennett JE, Dolin R,
Blaser MJ, editors. Mandell, Douglas and Bennett's Principles and Practice of Infectious Diseases. 8th ed. Philadelphia: Elsevier Saunders, 2015: 1194-1215.

9. Mentec H, Chosidow O, Lafaurie P, Darmon JY, Simon M, Roujeau JC, et al. Fasciite nécrosante à Neisseria meningitidis atteignant simultanément le bras et la jambe.[Necrotizing fasciitis, caused by Neisseria meningitidis, simultaneously involving an arm and a leg]. Ann Dermatol Venereol. 1993;120(12):889-91. French.PMID: 8074348

10. Carrascosa MF, Casuso-Sáenz E, Salcines-Caviedes JR. Neisseria meningitidis cellulitis.Int J Infect Dis. 2012;16(10):e760. DOI: 10.1016/j.ijid.2012.04.014 PMID: 22727693

11. Ozaki B, Kittai A, Chang S. Neisseria meningitidis as a cause of facial cellulitis. BMJ Case Rep. 2014:bcr2014203774. DOI: doi:10.1136/bcr-2014-203774 .PMID: 24626385

12. Abad R, Vázquez JA. Early evidence of expanding W ST-11 CC meningococcal incidence in Spain.J Infect. 2016;73(3):296-7. DOI: 10.1016/j.jinf.2016.06.010 PMID: 27387450

13. Ladhani SN, Beebeejaun K, Lucidarme J, Campbell H, Gray $\mathrm{S}$, Kaczmarski $\mathrm{E}$, et al. Increase in endemic Neisseria meningitidis capsular group W sequence type 11 complex associated with severe invasive disease in England and Wales. Clin Infect Dis. 2015;60(4):578-85. DOI: 10.1093/cid/ciu881 PMID: 25389259

14. Campbell H, Saliba V, Borrow R, Ramsay M, Ladhani SN. Targeted vaccination of teenagers following continued rapid endemic expansion of a single meningococcal group $\mathrm{W}$ clone (sequence type 11 clonal complex), United Kingdom 2015. Euro Surveill. 2015;20(28):21188. DOI: 10.2807/1560-7917. ES2015.20.28.21188 PMID: 26212140

15. Campbell H, Edelstein M, Andrews N, Borrow R, Ramsay M, Ladhani S. Emergency meningococcal ACWY vaccination program for teenagers to control group W meningococcal disease, England, 2015-2016.Emerg Infect Dis. 2017;23(7). DOI: 10.3201/eid2307.170236 PMID: 28409739

\section{License and copyright}

This is an open-access article distributed under the terms of the Creative Commons Attribution (CC BY 4.0) Licence. You may share and adapt the material, but must give appropriate credit to the source, provide a link to the licence, and indicate if changes were made.

This article is copyright of the authors, 2017. 